\title{
ANESTHESIA INFORMATION BOOKLET: A PAINLESSLY EFFECTIVE METHOD OF PATIENT EDUCATION
}

Angela C Cheung BSc, Barry A Finegan MB FRCPC, Jelka Lujic MD

Department of Anesthesiology and Pain Medicine, University of Alberta, 114 St - 89 Avenue, Edmonton, Alberta, T6 G2E1

\section{INTRODUCTION}

It is important to deliver appropriate information about anesthesia to patients prior to surgery. The current process of preoperative assessment frequently omits direct contact with anesthesiologists and consequently patients may be ill informed or inadequately informed on topics of relevance to anesthesiologists. We evaluated the effectiveness of an anesthesia information booklet in improving patient knowledge about perioperative instructions and the responsibilities of anesthesiologists.

\section{METHODS}

A graphical information booklet and ten-item questionnaire were developed internally and then reviewed by Plain Language Services with Canadian Health Projects so that the materials conformed to a grade 6 reading level. Following ethical approval and informed consent, patients were randomly assigned to receive an information booklet (Group 1) or no booklet (Group 2). Both groups were subsequently given the ten-item questionnaire aimed at testing the educational effectiveness of the booklet with respect to the risks of anesthesia, perioperative instructions, and the role of the anesthesiologist. A scoring system was developed and the data subjected to statistical analysis (including the Mann-Whitney Test, multiple logistical regression and one-way ANOVA in conjunction with Dunn' Multiple Comparisons Test).

\section{RESULTS}

Two hundred and fifty patients were included in the study. The mean score obtained by Group 1 was 8.9 88, while the mean score of those in Group 2 was 6037 (P $<0.0001$ ). Within Group 2, those born in Canada scored significantly higher than immigrants $(\mathrm{P}<0.001)$. Within Group 1, both Canadians and immigrants performed equally well $(\mathrm{P}>0.05)$. Detailed analysis of specific knowledge domains paralleled the overall findings noted above.

\section{DISCUSSION}

This study demonstrated the need for focused patient education about issues relating to anesthesia at the time of the preoperative visit. We did not assess the degree of compliance with the instructions contained in the booklet; however, one might assume that this occurred. Clearly informing patients of the key role of anesthesiologists cannot but strengthen the physician-patient relationship. The booklet was successful in communicating with audiences of diverse English reading ability, underscoring the importance of ensuring that medical information is delivered in a simple and readable fashion. 